\title{
El camino del caucho
}

\author{
Walter Ledermann
}

\section{The way of the rubber}

Investigations first by Markham, and then by Spruce, performed in the middle of multiple risks, in the deep of dense jungle, through the wild rivers and facing up natives many times hostile, brought the knowledge of the life cycle of Hevea brasiliensis, the rubber's tree, necessary for take its seeds to Asia, its adaptation to this continent and its culture at industrial level. Undoubtedly these men were the heroes of this history, but they were wise, modest and quite people, so the glory was for an entrepreneur decided and of scare scruples, like Wickham. And Brazil, as a good Latin American nation, sinned of naivety, improvidence and negligence, allowing itself the lost of an unimaginable fortune: the monopoly of the rubber. Because the many applications of rubber in medical practice, the history of this tree may interest our colleagues.

Key words: Rubber; Hevea brasiliensis; medicine.

Palabras clave: Caucho; Hevea brasiliensis; medicina.

\section{El caucho en medicina}

\section{L}

a historia del descubrimiento y explotación del caucho nos pareció digna de una gran película de aventuras, tanto que nos decidimos a escribirla bajo un título tomado del cine -El camino del gauchopelícula en que el gaucho desertor, un inexpresivo Rory Calhoun, intentaba huir con la bella Gene Tierney a Chile, siendo vencido, en una impresionante escena que los necios analfabetos llamarían "cúlmine", por la majestuosa blanca montaña que te dio por baluarte el Señor. En nuestra historia, sin embargo, ni la selva amazónica, ni el enorme río, ni los iracundos salvajes, ni los vastos océanos, impiden a Spruce, Markham, Wickham y Hooker llevar a cabo su hazaña.

Varias especies arbóreas, de distintas familias y géneros producen goma, pero no todos estos productos son tan útiles como el caucho, fabricado a partir del látex, que desde antes de la conquista de América los seringueiros extraían de la Hevea brasiliensis, haciéndole a puro cuchillo incisiones en el tronco. Cuando los españoles llegaron a las "Indias Orientales" se admiraron, entre otras cosas, de ver a los nativos jugar con pelotas de un material suave y duro a la vez, que rebotaba alegremente al ser arrojado al suelo ${ }^{1}$; siglos después, un norteamericano llamado Goodyear descubriría cómo hacer de esta goma, que se reblandecía con el calor y se hacía dura y quebradiza con el frío, un producto resistente e inmutable, convertido luego por la industria automovilística en una mina de oro: el caucho.

De todas las especies gomosas, la Hevea brasiliensis es la mejor; hoy en día produce algo así como el $98 \%$ del caucho mundial. Brasil, que podría haber tenido el monopolio, no supo ver, a fines del siglo XIX, su infinito potencial, y se lo dejó arrebatar por Inglaterra, país que se llevó el árbol a sus colonias asiáticas, básicamente a Ceilán, que ahora llaman Sri Lanka.

Este árbol del caucho pertenece a la familia Euforbidaceae, midiendo unos veinte a treinta metros de altura, excepcionalmente 45 , con un tronco recto y cilíndrico, de 30 a $60 \mathrm{~cm}$ de diámetro, de madera blanca y liviana. Su látex es blanco o amarillento y abundante hasta los 25 años de edad del árbol. La goma, que se obtiene sangrando el tronco con incisiones angulares en $\mathrm{V}$, contiene entre

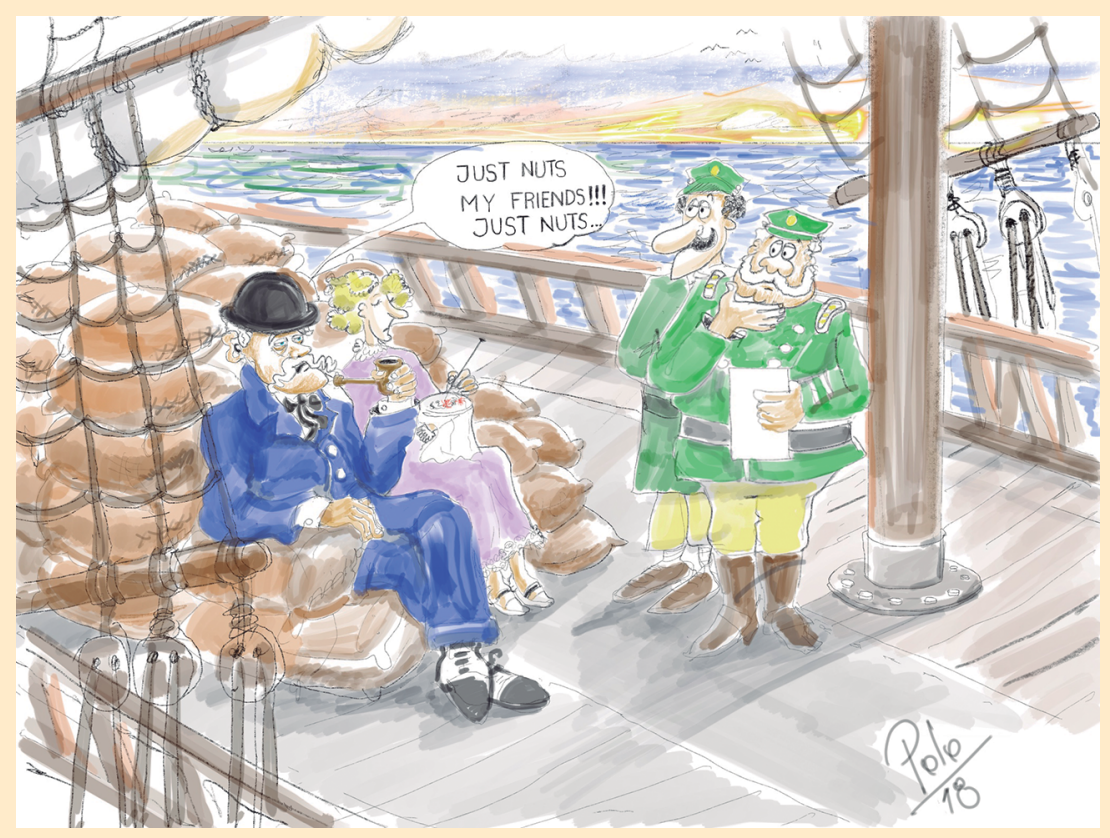

Centro de Estudios Humanistas Julio Prado.

Recibido: 5 de marzo de 2018 Aceptado: 13 de marzo de 2018

Correspondencia a: Walter Ledermann Dehnhardt oncemayor@gmail.com 
30 a $36 \%$ del hidrocarburo del caucho, $0,5 \%$ de cenizas, $1,5 \%$ de proteínas, $2 \%$ de resina y $0,5 \%$ de quebrachitol. En total, tenemos un $40,5 \%$ de componentes, menos de la mitad; el resto parece ser un enigma ${ }^{2}$.

La explotación sistemática del caucho se tradujo en un infinito número de aplicaciones, no sólo para la industria del automóvil, sino para muchas otras, entre ellas la de artículos médicos, como catéteres y sondas, que desplazaron los crueles y molestos instrumentos metálicos, sin olvidar colchonetas, mandiles, guantes, manguitos, pesarios, diafragmas y muchas otras que de momento no recordamos. Con el tiempo el caucho ha ido perdiendo algunas de sus aplicaciones médicas, al abrir camino a nuevos elementos más virtuosos, como los catéteres de elastómeros de silicona, substancia compuesta principalmente de silicio y oxígeno, muy resistente al calor y a la humedad, que también sirve para prótesis; o el politetrafluoroetileno (PTFE o Teflón ${ }^{\circledR}$ ), polímero similar al polietileno, en el que los átomos de hidrógeno han sido sustituidos por átomos de flúor. Este PTFE no reacciona con sustancias o tejidos, por lo que no sufre rechazo; siendo flexible y antiadherente se utiliza para prótesis, tejidos artificiales y vasos sanguíneos, e incluso en operaciones estéticas (body piercing); en óptica se emplea para proporcionar a las lentes cualidades antiestáticas, evitando la fijación del polvo.

Promisorios estudios se han hecho sobre la aplicación de grafeno al caucho, hasta llegar a un producto que podría servir para fabricar músculo artificial, combinando redes de carbono del espesor de un átomo con polímeros de monómeros. El grafeno se ha depositado sobre una película de caucho previamente estirada; a medida que el caucho se distiende, el grafeno separado se comprime; finalmente el complejo se estira de nuevo. "Puede controlarse el arrugamiento y el estiramiento de un área extensa de grafeno de espesor atómico, simplemente estirando y distendiendo una película de caucho, incluso a mano", en palabras del investigador Xuanhe Zhao, de la Universidad de Duke ${ }^{3}$.

Sin embargo, todavía la simple goma derivada del caucho sigue siendo de la mayor importancia, de modo que retomamos -o iniciamos-su historia.

\section{La portentosa investigación aventura de Spruce}

Richard Spruce (1817-1893), médico y naturalista inglés, de Yorkshire, se interesó desde pequeñito por la investigación aventura en historia natural. A los dieciséis años ya había hecho una lista de las plantas de Ganthorpe, su pueblo; a los diecinueve, escrito un libro sobre la flora del distrito de Malton; a los treinta y uno llegaría su gran oportunidad: una carta nada menos que de William Hooker, director de los Royal Botanic Gardens, en Kew.
Hooker planeaba una expedición botánica al Amazonas y andaba en busca de científicos intrépidos que quisieran integrarla.

-Come on! Join us- escribía a Spruce, con la tranquilidad que le daba saber que él mismo no se embarcaría en tan peligrosa aventura.

Spruce hesitó, pensando en su salud, nada apta para meterse en la selva: cuentan que era sordo de un oído, que no podía caminar mucho por el dolor causado por una parálisis de las piernas y que, de remate, parece que estaba tuberculoso. ¡Pamplinas, lo más bien que durante quince años recorrió la jungla de arriba abajo, enfrentó aterradores torrentes, hostiles aborígenes, escabrosos senderos, horrorosas culebras y venenosas arañas! ${ }^{4}$.

En estos quince años recorrió las selvas de Brasil, Venezuela, Guayanas, Ecuador y Perú, convirtiéndose en un gran conocedor de la flora y de la fauna amazónica. También de su pueblo - no hablemos de cultura para referirnos a las costumbres nativas- para lo cual debió sumar a las cuatro lenguas europeas que hablaba nada menos que veintiún dialectos de los aborígenes 5 . Pero, para nuestra sorpresa, estaba más interesado en el árbol de la quinina que en el del caucho, pensando en llevar la chinchona a India y obtener cantidades industriales de esta droga tan útil contra la malaria; no obstante, quiso su destino que se hiciera famoso por sus estudios sobre la Hevea, que posibilitaron luego la empresa de llevar sus semillas a Asia.

Aparte de sus conocimientos en lingüística, geología y geografía, y de su interés por los pueblos nativos, sus costumbres y creencias, nuestro hombre tenía un gran sentido del humor, que le permitía soportar sus males físicos, agravados a su retorno a Inglaterra, como lo muestra una carta escrita a un amigo en 1874:

"Dear friend - aquí estoy, nada bien y transformado, porque un día de la pasada semana un dentista me sacó cuatro dientes y ahora pertenezco al género Gymnostomum, pero cuando vengas espero haber desarrollado un completo doble peristoma".

Humor científicamente retorcido e incomprensible. Los Gymnostomum son musgos, que eran sus plantas favoritas, y no tienen dientes ${ }^{6}$. ¡Oh, that british humour!

\section{Sir Clements Robert Markham}

Este insigne aventurero supera en aventuras a Spruce, del cual era muy compatriota, pues también venía de Yorkshire, donde nació en julio de 1830. Era, por cierto, un gran botánico, un gran geógrafo, un regular escritor y un tremendo explorador: el simple resumen de sus hazañas superaría la total extensión de este artículo, por lo cual nos remitiremos, en lo posible, al asunto del caucho.

Markham tenía un buen contacto, su tía, la condesa 
de Mansfield, y pudo enrolarse con facilidad de la Royal Navy, llegando en su primer viaje a Valparaíso, tras pasar por Río y las Falkland. De ahí viajó a Callao: fue en Chile y en Perú donde aprendió castellano. Recibido de marino su familia logró meterlo en una expedición al Ártico en el HMS Assistance, buscando a un explorador perdido, al que no encontraron; de vuelta se retiró de la Royal Navy como teniente en 1852.

Ya como simple particular y con el dinero de su familia, viajó primero mucho por Perú, aprendió quechua, escribió libros y supo de la chinchona o quinina, por la que volvería seis años después para buscar ejemplares de la planta, así como sus semillas. Formando parte de su equipo venía Spruce: ahí fue donde se conocieron y juntaron plantitas, pero no de los mejores ejemplares, pues encontraron fuerte oposición nativa. Sin embargo, algunas de los que lograron llevar a Inglaterra pudieron prosperar en India, recibiendo Markham una buena parte de las utilidades, que no era tonto el hombre; además, recibió el título de Sir, que los ingleses apetecen mucho ${ }^{7}$. Alentado por este éxito, recomendó llevar el algodón peruano y la ipecacuana brasileña a India.

Y, por último, quiso llevarse de Brasil también el caucho; el resto de su fabulosa vida no nos interesa ahora y lo dejaremos para otra hipotética ocasión. Por entonces nuestro héroe era funcionario del gobierno inglés, como geógrafo destacado; por tanto, informó oficialmente de la utilidad del árbol del caucho, que era "susceptible de domesticación”. Pero Sir Joseph Hooker, que dirigía el Royal Garden en Kew, sólo tomó interés en el asunto después de conocer los trabajos de Spruce y comenzó a urgir a Markham para que le mandara semillas. Entre 1873 y 1875 éste hizo tres envíos, pero las semillas no llegaron a Inglaterra aptas para la siembra, pues su alto contenido en látex las hacía fermentar muy rápido y su mucho aceite también: de las enviadas en 1873 alcanzaron a germinar doce, pero murieron pronto ${ }^{8}$.

Hacía falta un aventurero más decidido para realizar la hazaña: éste sería Wickham, llamado el primer biopirata.

\section{Sir Henry Alexander Wickham}

Hooker, el director de los Kew Garden, conocía a este Wickham, un colono inglés establecido en Santarem, Brasil, y le ofreció diez libras esterlinas por cada mil semillas viables de árbol del caucho, puestas en Kew. Así se inició esta oscura historia.

Henry Alexander Wickham, más tarde Sir, vivió entre 1846 y 1928 una existencia aventurera e increíble. A los veinte años ya estaba en Nicaragua, cazando aves exóticas, cuyas plumas enviaba a Inglaterra para la confección de sombreros de señoras. Un año después estaba en el delta del Orinoco; luego cruzó el Río Negro para llegar a Ma- naos, sangrando árboles del caucho donde los encontrara; finalmente por el Amazonas hasta Pará. Fue a Inglaterra, se casó con Violet Carter, quien ilustraría todas sus aventuras, y volvió a Brasil, estableciéndose en Santarem, actualmente municipio de Pará, en la confluencia de los ríos Tapajos y Amazonas. Allí, tras diez años de aventuras, su hora triunfal llegó en 1876, con la oferta de Hooker.

Los hechos siguientes se han discutido mucho: hay quienes alaban a Wickham y muchos más que lo tratan de ladrón y biopirata, acusándolo de haber robado a Brasil la preciosa Hevea, con incalculable perjuicio económico ${ }^{9}$. Cuenta el acusado que "los escasos plantadores de Santarem fueron sacudidos por la noticia de la llegada de un buque de linea totalmente equipado, junto a una invitación para ir a cenar a bordo de este S.S. Amazonas". Tras la buena comida y seguramente después del segundo whisky, el capitán George Murray le contó a Wickham sus tribulaciones: dos marineros habían desertado, lo cual al colono no le interesó, y no tenía carga para su viaje de retorno a Inglaterra, lo cual le hizo parar las orejas:

- ¡Pero yo tengo! -exclamó-. Es decir, lo tendré en unos días, cuando pase de vuelta, ya que me ha dicho que aun debe ir río arriba. El Dr. Joseph Hooker, director del Royal Garden en Kew le pagará llegando a Liverpool.

Esta oferta era nada menos que un bluf de póker, pues Wickham, en ese mismísimo momento, no tenía carga alguna. Pero antes que S.S. Amazonas levara anclas, ya estaba en una canoa subiendo por el Tapajos en busca de las famosas 70.000 semillas de Hevea brasiliensis que enviaría a Kew y le harían inmortal. Y aquí empiezan las controversias, pues hasta su misma esposa dice que compró algunas, otros objetan que era imposible recolectarlas en pocos días, y etcétera, etcétera, pero Wickham cuenta que contrató muchos nativos para recoger las caídas en cestas tejidas con caña por las niñas nativas. Envolviéndolas, tras un breve secado, en hojas de banana (un aporte de Spruce) para preservar su viabilidad, las llevó a casa y esperó.

Cuando el S.S. Amazonas regresó a Santarem, el capitán Murray se encontró con un cargamento de 70.000 semillas muy bien embaladas y los pasajeros Henry y Violeta Wickham. Y aquí viene lo oscuro del asunto: el acta de entrada de la mercadería por la aduana de Liverpool no registra que el buque se haya detenido en Santarem ni que cargara semillas de Hevea, pero sí declara 819 sacos de nueces de Pará, en tanto que en el puerto de Belem, a la salida del Amazonas, el cónsul británico explicó a la aduana brasileña que la carga era de "especímenes botánicos extremadamente delicados para los Kew Royal Botanic Gardens de Su Majestad Británica”. Ante esta declaración los empleados de aduana brasileña, con la típica sumisión de los hispánicos ante el hombre blanco, colaboraron y dejaron salir a toda prisa al S.S. Amazonas, el cual llegaría a Liverpool el 10 de junio de 1876. Allí 
su preciosa carga sería trasladada de inmediato a Kew en un tren fletado por Wickham, para ser sembrada al día siguiente, el 14 de junio. La hazaña estaba consumada ${ }^{10}$.

De las 70.000 semillas germinaron 2.800 , lo que hace un $4 \%$. Las plantitas se metieron en unas cajas Wardian, con base de madera llena de tierrecita, vidriadas por todos los lados y con manillas en su base; en suma, mini-invernaderos, precursores de los terrarios actuales, fruto del ingenio de un médico inglés apasionado por la botánica, Nathaniel B. Ward, quien también merece un crédito en esta historia. La idea era mandar las cajas a Birmania, pero hubo algunas dificultades y Hooker las despachó a Ceilán, hoy Sri Lanka, desde donde más tarde el cultivo se expandiría a Malasia y otros países del sudeste asiático.

Richard Evans, un botánico de Harvard, ha defendido a Wickham ${ }^{12}$ diciendo que en esa época Brasil no prohibía la exportación de semillas y que no hubo ningún secreto en el embarque; sin embargo, el registro de la aduana inglesa, una institución seria, no deja dudas acerca de la maliciosa declaración de carga, ¡nueces de Pará!, y la inusitada presencia del cónsul inglés en el embarque, hablan de dolo, que la Real Academia define como "engaño, fraude, simulación", por no decir malicia, esto es, "maldad". También, queriendo minimizar el perjuicio, se afirma que la técnica de producción brasileña era atrasada, que sus árboles estaban afectados por un hongo, el tizón, y que en, en todo caso, en Asia el clima era más favorable para la domesticación y cultivo de la Hevea brasiliensis: en suma, que hubo un beneficio para la humanidad... ¡Menos mal que al arbolito no le quitaron el apellido!

\section{Resumen}

Las investigaciones de Markham, primero, y luego de Spruce, llevadas a cabo en medio de múltiples peligros, internándose en selvas espesas, vadeando salvajes ríos y enfrentando nativos muchas veces hostiles, permitieron conocer el ciclo de vida del árbol del caucho para el traslado de sus semillas, su aclimatación en Asia y cultivo a nivel industrial. Indudablemente ellos fueron los héroes de esta epopeya al hacer esta investigación venturosa, pero los sabios son modestos y callados, de manera que la gloria se la llevó un empresario decidido y de pocos escrúpulos cual Wickham. En cuanto a Brasil, como buena nación latinoamericana, pecó de ingenuidad, improvisación y negligencia, dejándose arrebatar una inimaginable fortuna: el monopolio del caucho. Creemos que las múltiples aplicaciones médicas del caucho, haciendo menos dolorosos los exámenes y procedimientos, pudieran ser de interés para nuestros colegas.

\section{Referencias bibliográficas}

1.- Díaz del Castillo, Bernal. Historia Verdadera de la Conquista de la Nueva España. Madrid 2011. Galaxia Gutenberg-RAE.

2.- Hevea brasiliensis. Plants of the world online. Kew Science 2017. "Hevea brasiliensis (Willd. ex A. Juss.) Müll. Arg".

3.- Jianfeng Zang, Seunghwa Ryu, Nicola Pugno, Qiming Wang, Qing Tu, Markus J. Buehler, Xuanhe Zhao. Multifunctionality and control of the crumpling and unfolding of large-area graphene. Nature Materials 2013. DOI: $10.1038 /$ nmat3542.

4.- Pearson M. Richard Spruce: Naturalist and Explorer. Hudson History, Settle, Yorkshire. 2004.

5.- Spruce, Richard. Notes of a Botanist on the Amazon \& Andes: being records of travel on the Amazon and its tributaries, the Trombetas, Río Negro, Uaupés, Casiquiari, Pacimoni, Huallaga, and Pastasa; as also to the cataracts of the Orinoco, along the eastern side of the Andes of Peru and Ecuador, and the shores of the Pacific, during the years 1849-1864. Vol. I-II. Edited by Alfred Russel Wallace. Macmillan, London 1908. https://dx.doi.org/10.5962/bhl. title. 17908 .

6.- Ayers, E. Richard Spruce and the Trials of Victorian Bryology The Public Domain Review. https:// publicdomainreview.org/2015/10/14/richard-spruce-and-thetrials-of-victorian-bryology/

7.- Tully, J. The Devil's Milk: A Social History of Rubber. NYU Press 2011.

8.- Ponting, Clive A New Green History of the World: The Environment and the Collapse of Great Civilizations. New York 2007. Penguin Books. p. 183. ISBN 978-0-14-3038986.

9.- Jackson, J. The thief at the end of the world. Rubber, Empire and the obsessions of Henry Wickham. Duckworth Overlook, London 2008. www.ducknet.co.uk

10.- Loadman, J. Tears of the tree. The story of rubber. A modern marvel. Oxford 2005, Oxford University Press; pp. 85-107.

11.- Evans Schulter, R. The odyssey of the cultivated rubber tree. Endeavour, New Series 1977; 1 (3/4): 133-8. 23-Nota histórica (prueba final) 